\title{
Straddling and/or overriding mitral valve
}

INSERM

\section{Source}

INSERM. (1999). Orphanet: an online rare disease and orphan drug data base. Straddling and/or overriding mitralvalve. ORPHA:99064

A rare, congenital, non-syndromic heart malformation characterized by an abnormal attachment of the mitral chordae to both ventricles. Straddling mitral valve is usually associated with conotruncal anomalies, most commonly double outlet right ventricle or transposition of the great arteries. Overriding mitral valve is characterized by a mitral annulus committed to the two ventricular chambers, where the mitral valve is shared between the ventricles. Straddling and overriding mitral valve can occur together or in isolation. 